\title{
O ETERNO CONFLITO ENTRE LIBERDADE E CONTROLE: $O$ CASO DA VACINAÇÃO OBRIGATÓRIA
}

Ninguém é ingênuo a ponto de imaginar que, no século XXI, seja possível encontrar qualquer governo imune à força política diretamente derivada da força econômica das grandes empresas globais. Com efeito, os governantes têm o orgulho de se descreverem como parceiros/agentes de marketing das empresas que têm seus respectivos Estados como sede social ${ }^{1}$. Do mesmo modo, essa ingenuidade não é mais possível quando se trata da fronteira entre o jurídico e o político. O caso brasileiro é exemplar, mas, para fugir da acusação de subjetividade, convém examinar o que se deu na regulação do consumo de tabaco na Áustria: o Partido da Liberdade (FPÖ) exigiu, para aderir à coalisão que permitisse a formação de um governo, a retirada da interdição total de fumar nos bares, restaurantes e discotecas, prevista na legislação de 2015 e que deveria entrar em vigor no próximo $1^{\circ}$ de maio ${ }^{2}$.

Uma resposta imaginada na segunda metade do século XX, durante o período de extraordinário crescimento do Estado Social de Direito na Europa, visaria especialmente a preservar o direito. Sistematizada, sobretudo por Luhmann, a teoria sistêmica do direito propõe a aplicação da noção de sistema desenvolvida na outra metade do século, permitindo a compreensão dos insumos, processos e produtos que caracterizam cada setor da vida social e, portanto, possibilitando melhor controle de eventuais disfuncionamentos. Muito criticada desde sua enunciação, especialmente no que respeita exatamente à relação do sistema com seu ambiente, não há qualquer dúvida de que tal teoria revela sua utilidade para a eventual preservação do direito como um sistema social, que atua de acordo com seus próprios processos, gerando o direito a partir do direito.

No terceiro milênio, é preciso considerar, contudo, que talvez essa sonhada autonomia dos sistemas sociais não seja mais possível no mundo absolutamente em rede. Parece restar apenas um caminho para que a humanidade preserve os direitos, conquistados sempre com muita luta: a extensão dos mecanismos democráticos, e das possibilidades de sua utilização, formalizados na engrenagem jurídica. Apenas o controle judicial dos processos democráticos de criação e implementação dos direitos pode ser capaz de assegurar alguma autonomia ao direito deste tempo. Essa talvez seja a nobre função do sistema jurídico no século XXI: garantir que o direito declarado seja plenamente realizado na vida das pessoas concretas.

\footnotetext{
${ }^{1}$ Os exemplos são inúmeros, verificáveis especialmente quando das chamadas "visitas de Estado" e, à profusão, por ocasião da realização do Fórum Econômico de Davos.

${ }^{2}$ GAUQUELIN, B. Coup de tabac sur la santé publique autrichienne. M le magazine du Monde, 30 déc. 2017. p. 15.
} 
Este mundo complexo, totalmente interconectado, é o cenário do conflito entre os vários direitos formalmente declarados, cuja resolução implica tanto a preservação dos valores que os subsidiam quanto sua efetiva realização no caso concreto $^{3}$. O procedimento ganha, portanto, um lugar privilegiado. É preciso primeiramente interpretar o texto legal. Em seguida, é necessário esclarecer se tratasse de norma que traduz uma regra, a ser, portanto, totalmente realizada ou excluída do respectivo sistema jurídico ou se é o caso de um princípio. Finalmente, nesta hipótese, deve-se identificar, no caso concreto, qual princípio expresso naquela norma deverá prevalecer, sempre buscando a otimização de todos os princípios envolvidos no conflito. E todo esse procedimento deve ser claramente expresso talvez se possa dizer mesmo didaticamente expresso - para possibilitar o controle judicial neste mundo complexo.

É nesse cenário social, econômico e cultural, mas particularmente nesse ambiente jurídico, que deve ser examinada a obrigação de se vacinar ou de fazer vacinar seus filhos, exigência que vem se afirmando na contemporaneidade. Com efeito, na França, as crianças nascidas a partir de $1^{\circ}$ de janeiro de 2018 deverão ser vacinadas contra 11 doenças infecciosas para poderem frequentar as creches ou escolas. O governo justifica a ampliação do número de vacinas obrigatórias (eram apenas três anteriormente) em nome da segurança, pois, com apenas $70 \%$ da população imunizada contra a meningite $\mathrm{C}$ ou $80 \%$ tendo recebido o reforço da vacina contra o sarampo, a caxumba e a rubéola, a proteção contra eventual surto de tais moléstias não está assegurada. Por outro lado, uma parte da população anda incomodada com a gestão incompetente das últimas crises sanitárias. Veja-se o caso da vacina contra a hepatite B: a Assembleia Mundial da Saúde, em 1992, recomendou a introdução da vacinação universal contra a hepatite $B$ nos programas nacionais de vacinação, e continua entusiasta da vacinação desde o nascimento como um meio seguro e eficaz de prevenção da doença ${ }^{5}$. É evidente que a vacina proporcionou e segue proporcionando boa renda para seus fabricantes, apesar de não ter se tornado acessível a todos, como recomendado pela Organização Mundial da Saúde. Nos anos 1990, a França adotou a estratégia de vacinação dos adolescentes, idade mais sujeita ao aparecimento da esclerose em placas. Assim, apesar de nunca ter sido comprovado o aumento de casos desse tipo de doença neurológica causado pela vacina, os médicos se sentiram pouco amparados para recomendá-la. Também a

\footnotetext{
${ }^{3}$ Trata-se de tema amplamente discutido na teoria jurídica contemporânea. Excelente o artigo do professor Virgílio Afonso da Silva sobre o tema, sintetizando a tese apresentada ao concurso de Professor Titular (SILVA, V. A. O conteúdo essencial dos direitos fundamentais e a eficácia das normas constitucionais. Revista de Direito do Estado, v. 4, p. 23-51, 2006. Disponível em: <https://constituicao.direito.usp.br/wpcontent/uploads/2006-RDE4-Conteudo_essencial.pdf>).

${ }^{4}$ FORTY-FIFTH WORLD HEALTH ASSEMBLY Hbk Res., Vol. III (2nd ed)f 1.15.3; 1.16.1 (Twelfth plenary meeting, 13 May 1992 - Committee A, third report) GENEVA, 4-14 MAY 1992.

${ }^{5}$ ORGANISATION MONDIALE DE LA SANTÉ - OMS. Hépatite B. Aide-mémoire, N. 204, Juil. 2017. Disponível em: <http://www.who.int/mediacentre/factsheets/fs204/fr/>.
} 
gestão da pandemia de gripe causada pelo vírus H1N1 foi desastrosa para a confiança dos franceses, que reprovaram a ministra da Saúde de então pela compra de grandes quantidades do único medicamento recomendado para seu tratamento e de doses de vacinas pouco eficientes contra o vírus em questão, especialmente quando se verificou que a pandemia era de pouca infectividade e virulência. Sobrou igualmente a constatação dos altos lucros proporcionados aos laboratórios fabricantes ${ }^{6}$. $\mathrm{E}$ as estruturas encarregadas do controle do medicamento foram igualmente questionadas quando do escândalo do Mediator, que teria ocasionado entre 500 e 2.000 mortes; apesar de haver um alerta desde 1997, esse medicamento só foi retirado do mercado em novembro de 2009 e provocou uma reforma no sistema de controle de medicamentos ${ }^{7}$. Em suma, a notícia da passagem de três para 11 vacinas obrigatórias encontra comunidades muito reticentes: "uma suspeição em relação a tudo que é químico", "uma decisão brutal que infantiliza os pais", "algumas delas foram adotadas apenas por razões comerciais".

Igualmente, é nesse mesmo cenário que deve ser examinada a obrigação imposta pela Região Emilia Romagna, na Itália, aos médicos e demais profissionais de saúde de se vacinarem contra determinadas doenças, sob pena de serem transferidos de serviço. Com efeito, desde agosto de 2017, dez vacinas passaram a ser obrigatórias para as crianças que frequentam os berçários, creches e escolas ${ }^{9}$. A regulamentação dessa lei prevê a apresentação, pelos gestores na educação e na saúde, da declaração da situação vacinal de seu pessoal ${ }^{10}$. Outras regiões italianas pensam seguir o exemplo da Emilia, entre elas Toscana, Lazio, Lombardia, Piemonte e Veneto ${ }^{11}$.

Tem-se, portanto, uma ampliação da obrigação vacinal, impondo inclusive pesadas restrições aos infratores (impossibilidade de frequentar as escolas ou de manter seu posto de trabalho, por exemplo). Essa ampliação é acompanhada, entretanto, de sérias dúvidas a respeito da segurança e da efetividade das vacinas (caso da vacina contra a hepatite $\mathrm{B}$ ou contra a febre amarela, na diluição hoje proposta no

${ }^{6}$ FRANCE. Sénat. Session Ordinaire de 2010-2011. La gestion d'une crise sanitaire: la pandémie de grippe A (H1N1). Rapport d 'information. Fait au nom de la commission des affaires sociales (1) sur l'étude de la Cour des comptes relative à l' utilisation des fonds mobilisés pour la lutte contre la pandémie grippale $A$ (H1N1), Par M. Alain Milon. Disponível em: <http://www.senat.fr/rap/r10-270/r10-270_mono.html>.

${ }^{7}$ L'AFFAIRE Mediator et la sécurité des médicaments: dossier documentaire. Service documentation. Mise à jour: 8 octobre 2012. Disponível em: <https://documentation.ehesp.fr/wp-content/uploads/2012/10/ DO_AffaireMediator_20121008.pdf>.

${ }^{8}$ BÉGUIN, F. En Ardèche, voyage au pays de la défiance. Le Monde, 31/12/2017.p. 6. Disponível em: <http:// www.lemonde.fr/sante/article/2017/12/30/vaccins-dans-le-canton-des-vans-en-ardeche-voyage-au-paysde-la-defiance_5235962_1651302.html?xtmc=vaccins_obligatoires\&xtcr=2>.

${ }^{9}$ Legge 31 luglio 2017 , n. 119. Conversione in legge, con modificazioni, del decreto-legge 7 giugno 2017, $n$. 73, recante disposizioni urgenti in materia di prevenzione vaccinale.

${ }^{10}$ ITALIA. Ministero della Salute. Direzione Generale della Prevenzione Sanitaria. Ufficio V - Prevenzione delle Malattie Trasmissibili e Profilassi Internazionale. Disponível em: <http://www.trovanorme.salute.gov.it/ norme/renderNormsanPdf?anno=2017\&codLeg=60282\&parte=1\%20\&serie =null>.

${ }^{11} \mathrm{BOCCI}, \mathrm{M}$;; DI RAIMONDO, R. L'ora del vaccino obbligatorio per i medici. La Republica, 7/1/2018. Disponível em: <http://ricerca.repubblica.it/repubblica/archivio/repubblica/2018/01/07/lora-del-vaccino-obbligatorio-per-imedici04.html>. 
Brasil $\left.^{12}\right)$. A boa-fé, ou ao menos a competência, dos governantes é também posta em xeque quando se verificam os altos lucros dos laboratórios produtores das vacinas e a incapacidade de estenderem sua distribuição a todas as populações necessitadas, com a garantia de condições de segurança e eficácia. O que se pode legitimamente esperar do comportamento do sistema judicial frente a essa situação?

Em primeiro lugar, é preciso compreender o que é protegido pelas referidas leis. E a resposta é complexa, pois, ao mesmo tempo em que se almeja proteger a saúde de cada pessoa que receberá a vacina, visa-se a proteger a coletividade com a expressiva diminuição dos agentes causadores das moléstias evitáveis pela vacina. Tem-se, então, caracterizada a proteção ao direito fundamental à saúde, não só individual como também coletiva. Quanto às possíveis restrições postas à implementação do direito à saúde, podem-se enumerar o direito à liberdade individual, que assegura a escolha de não se submeter aos riscos de efeitos adversos da vacina ou o direito à educação, ou ainda, o direito à liberdade profissional. Isso sem esquecer a inclusão do processo de produção e comercialização de medicamentos e vacinas no sistema capitalista, que implica a auferição de lucro. No caso brasileiro, todos esses direitos fundamentais encontram abrigo expresso no texto constitucional ${ }^{13}$. E não se diga que o Estado não está obrigado a intervir, regulando ou regulamentando as situações concretas para a realização de cada um dos direitos declarados ${ }^{14}$. Bem ao contrário, ele está amplamente obrigado à proteção de cada um desses direitos fundamentais. Espera-se, portanto, que o sistema judicial fundamente, argumentando amplamente a partir da consideração da situação concreta, a opção pela proteção adotada.

E aqui se introduz a indispensável apreciação judicial da efetiva realização democrática requerida em todo Estado Democrático de Direito. Com efeito, é evidente que a exigência da origem democrática do direito e de sua realização sob controle democrático vem se tornando universal ${ }^{15}$. Isso significa que a inexistência de ampla participação popular (leiga e especializada), tanto no momento de fixação da norma que exprime o direito - e seu alcance - quanto na sua realização no caso concreto, dificultará enormemente o alcance de uma solução justa pelo sistema jurídico. Mas não só: a solução justa exige do sistema jurídico a apreciação dos

\footnotetext{
${ }^{12}$ FIORAVANTI, Carlos. Examinando a vacina contra febre amarela. Pesquisa FAPESP, ed. 264, fev. 2018. Disponível em: <http://revistapesquisa.fapesp.br/2018/02/02/examinando-a-vacina-contra-febre-amarela/>.

${ }^{13} \mathrm{Artigos} 6^{\circ} \mathrm{c} / \mathrm{c} 196$ (direito à saúde); artigo $5^{\circ}$ (direito à liberdade); artigo 205 (direito à educação); artigo $5^{\circ}$, inciso XIII (liberdade de exercício profissional); artigo 170, inciso II (ordem econômica baseada na propriedade privada). BRASIL. Constituição da República Federativa do Brasil de 1988. Disponível em: <http://www.planalto.gov.br/ccivil_03/constituicao/constituicaocompilado.htm>.

${ }^{14}$ No caso brasileiro, expressamente: artigos 197 e 200, inciso I (obrigando a regulamentação, fiscalização e controle das ações e serviços de saúde e, particularmente, dos produtos e substâncias de interesse para a saúde); artigo 170, incisos I e III (sujeitando a ordem econômica à soberania nacional e à função social da propriedade). BRASIL. Constituição da República Federativa do Brasil de 1988, cit.

${ }^{15}$ Examinei o tema em: DALLARI, Sueli Gandolfi. A internacionalização das regras jurídicas no campo do direito sanitário. In: LOURENÇO, Cristina Silvia Alves; OLIVEIRA, Frederico Antonio Lima de (Orgs.). Estado, direito e sociedade: os desafios da nova ordem social. 1. ed. Rio de Janeiro: Lumen Juris, 2016. v. 2, p. 205-226.
} 
diferentes direitos envolvidos na situação concreta e a ampla argumentação motivando a decisão em cada hipótese.

A obrigação vacinal não foge às referidas exigências: ampla participação popular; ampla argumentação processual, fundada na situação concreta, esclarecendo os limites do direito pedido; ampla argumentação processual esclarecendo os limites da regulamentação dos direitos incidentes na situação concreta - tudo isso levando a uma decisão processual motivada amplamente na ponderação dos direitos incidentes na situação concreta. Todas as partes envolvidas no processo judicial encontram-se, assim, igualmente obrigadas à ampla argumentação. E mais: todo o sistema sanitário encontra-se obrigado a promover a ampla participação popular (leiga e especializada) a respeito do alcance de cada um dos direitos envolvidos na obrigação de se vacinar. Essa é a única maneira de possibilitar que o sistema jurídico determine o justo equilíbrio entre liberdade e controle no caso da vacinação obrigatória no mundo complexo do século XXI.

Sueli Gandolfi Dallari

Editora científica 